\title{
Acute severe asthma: Part 2. Current therapy
}

\author{
ROBERT G. GARMON, DO \\ RICHARD B. ZEMENICK, DO
}

Acute severe asthma is an extremely common and serious public health problem in the United States. Current optimum therapy of acute severe asthma includes supplemental oxygenation, nebulized $\beta$-adrenergic receptor agonist therapy, and prompt use of glucocorticosteroids. In view of its low therapeutic index and the availability of more effective, less toxic agents, theophylline is no longer considered a first-line treatment. Ipratropium bromide combined with $\beta$ agonist may augment bronchodilator responsiveness.

(Key words: Status asthmaticus, bronchodilators, anticholinergics, methylxanthines, hydration therapy, mechanical ventilation)

Bronchial asthma is a common disease afflicting $3 \%$ or more of the population in the United States. ${ }^{1}$ Mortality from asthma has increased in the United States and other western countries during the past 10 years. Inadequate therapy has been proposed as one of the

From Texas College of Osteopathic Medicine (TCOM), Fort Worth, where at the time this paper was written, Dr Garmon was associate professor of medicine, Department of Medicine, and Dr Zemenick was associate professor, Division of Emergency Medicine. Currently, Dr Garmon is clinical associate professor in the Department of Internal Medicine, TCOM, and medical director of the Pulmonary Function Laboratory and Respiratory Therapy Departments at Campbell Memorial Hospital, Weatherford, Tex. Dr Zemenick is now assistant attending staff, St Paul Medical Center, Dallas, Tex.

Reprint requests to Robert G. Garmon, DO, 716 E Anderson, Suite 103, Weatherford, TX 76086. reasons for the increased mortality rate. Controversy has surrounded the appropriate treatment throughout the past several decades. Which medications at what dosages and administered by what route are areas of debate. Current modes of therapy include oxygen, $\beta$ adrenergic receptor agonists, corticosteroids, anticholinergics, and methylxanthines.

\section{Oxygen therapy}

Persons having an acute asthmatic attack are frequently hypoxemic. ${ }^{2,3}$ Additionally, arterial oxygen tension may decreases temporarily in patients after initiation of bronchodilator therapy, ${ }^{4,5}$ which decrease probably represents a transitory ventilation perfusion mismatch due to sputum mobilization in the airways or increased cardiac output (or both). An oxygen tension of at least $60 \mathrm{~mm} \mathrm{Hg}$ is necessary to maintain adequate hemoglobin saturation. Oxygen should be administered. Nasal $\mathrm{O}_{2}$ flows of $2 \mathrm{~L} / \mathrm{min}$ to $6 \mathrm{~L} / \mathrm{min}$ are usually adequate to control hypoxemia. Supplemental oxygen is unlikely to cause or aggravate hypercapnia in patients with acute severe asthma. Oxygen should also be used to nebulize medication.

\section{Bronchodilator therapy}

$\beta$-Adrenergic receptor agonist aerosol therapy is the cornerstone of treatment of acute severe asthma. In the past, epinephrine was considered the agent of choice; however, it is the least potent bronchodilator of all of the $\beta$-agonists and its $\alpha$ and $\beta_{1}$ effects produce a much higher incidence of side effects than do $\beta_{2}$-agonists. ${ }^{6,7}$ The $\beta_{2}$-agonists include albuterol, terbutaline, 
metaproterenol, and pirbuterol. Compared with the catecholamines epinephrine, isoproterenol, and isoetharine, the $\beta_{2}$-agonists are superior bronchodilators, have a longer duration of action, and produce fewer side effects. ${ }^{7-12}$

Aerosol inhalation is the preferred route for administering $\beta_{2}$-agonists. ${ }^{13-16}$ Aerosol therapy provides a more rapid onset of action and more bronchodilation than oral therapy, ${ }^{14,15,17}$ and is equal to intravenous administration, ${ }^{18-20}$ but with fewer side effects. ${ }^{19,20}$ Aerosol therapy may be given by metered dose inhaler (MDI), jet nebulizer, or dry powder inhalation. Metered dose inhalers are more efficient than nebulization at delivering medication to the airways. ${ }^{13}$ However, many patients, even during routine administration are unable to correctly use the MDI. ${ }^{21,22}$ Spacer devices such as the Aerochamber (Forest Pharmaceuticals, St Louis, Mo), Breathancer (Perlos, Finland, distributed by Geigy Pharmaceuticals, Ardsley, NY), or InspirEase (Schering Corp, Kenilworth, $\mathrm{NJ}$ ) have improved the reliability of medication delivery by the MDI. ${ }^{23}$

To provide equipotent bronchodilation, nebulizer treatment requires larger doses. ${ }^{24-26} \mathrm{Nebu}$ lized medication should be diluted to a total volume of $4.0 \mathrm{~mL} .^{27}$ This volume is required to avoid significant medication loss because of adherence to the chamber and tubing. Additionally, compressed gas flow rate should be equal to or greater than $6 \mathrm{~L} / \mathrm{min}$ to ensure appropriate aerosol particle size.

Debate exists as to which aerosol delivery technique is best. ${ }^{13,28}$ Patients having acute severe episodes are more likely to respond to updraft nebulizer therapy than to the MDI with a spacer. ${ }^{24,29,30}$ In one study, $21 \%$ of the patients having acute episodes were unable to use the MDI device effectively. ${ }^{31}$ Studies finding the MDI with spacer equally as effective as nebulization either studied patients with nonacute disease $\mathrm{e}^{22,32-34}$ or compared nebulization therapy with MDI therapy that involved a disproportionately high $\beta$-agonist dosage ${ }^{35}$ (10 sprays $=200 \mu \mathrm{g}$ per spray $[2 \mathrm{mg}$ of terbutaline] compared with 2 sprays [ $400 \mu \mathrm{g}$ of terbutaline] normal dose). In children, use of a dry powder inhaler is less effective than an MDI with spacer or nebulization in treating acute bronchospasm. ${ }^{36,37}$ One study found that $67 \%$ of children could not generate an inspiratory flow rate needed for effective use of a dry powder inhaler ${ }^{38}$ We are unfamiliar with any studies comparing the effectiveness of a dry powder inhaler with other aerosols in the patient with acute severe asthma.

In recommended doses, the $\beta_{2}$-agonists albuterol, metaproterenol, pirbuterol, and terbutaline are essentially equipotent bronchodilators and possess similar duration of action and side effects. ${ }^{8,14,16,31,39-44}$ All $\beta$-agonists may cause lowering of the serum potassium levels. ${ }^{45,46}$ Terbutaline produces a substantially more intense and prolonged hypokalemic effect than albuterol. ${ }^{45}$

During acute severe episodes of asthma, larger doses of bronchodilator are required to achieve maximal effect. ${ }^{13,28,47,48}$ Additionally, a longer duration of therapy is associated with a lower relapse rate ${ }^{49}$ Only about one third of acute asthmatic episodes can be terminated successfully within 1 hour. ${ }^{50}$ In a 1989 study, ${ }^{47}$ "high dose" albuterol $(0.15 \mathrm{mg} / \mathrm{kg})$ was nebulized to children at 20-minute intervals, up to six doses. Inhalations, which lasted about 15 minutes, did not exceed $5 \mathrm{mg}$ per dose for children weighing less than $40 \mathrm{~kg}$. This dose was found to be significantly superior to a lesser dose tested, and no major side effects were noted. The mean peak serum levels were 19.8 $\mu \mathrm{g} / \mathrm{mL}$. This value compares closely with peak serum levels of $14.1 \mu \mathrm{g} / \mathrm{mL}$ and $18 \mu \mathrm{g} / \mathrm{mL}$ noted after oral ingestion of $4 \mathrm{mg}$ of albuterol..$^{51,52}$

Two other studies have found that $15 \mathrm{mg}$ of nebulized albuterol in adults is a superior bronchodilator dose to $1.25 \mathrm{mg}, 2.5 \mathrm{mg}, 5 \mathrm{mg}$, and $10 \mathrm{mg} .{ }^{53,54}$ Light and coauthors ${ }^{54}$ stated that the optimal dose of albuterol is $10 \mathrm{mg}$, whereas Nelson and associates ${ }^{53}$ concluded that a modest dose $(2.5 \mathrm{mg})$ of nebulized albuterol will result in a less-than-optimal bronchodilator response in many patients. In the United Kingdom, higher doses of albuterol aerosol, up to $10 \mathrm{mg}$, are approved for acute severe asthma. ${ }^{55}$

Inhaled $\beta$-agonist therapy has been shown to be safe during pregnancy. ${ }^{56}$ Terbutaline is considered by several authorities as the best $\beta$-agonist to use in the pregnant asthmatic pa(continued on page 347 ) 


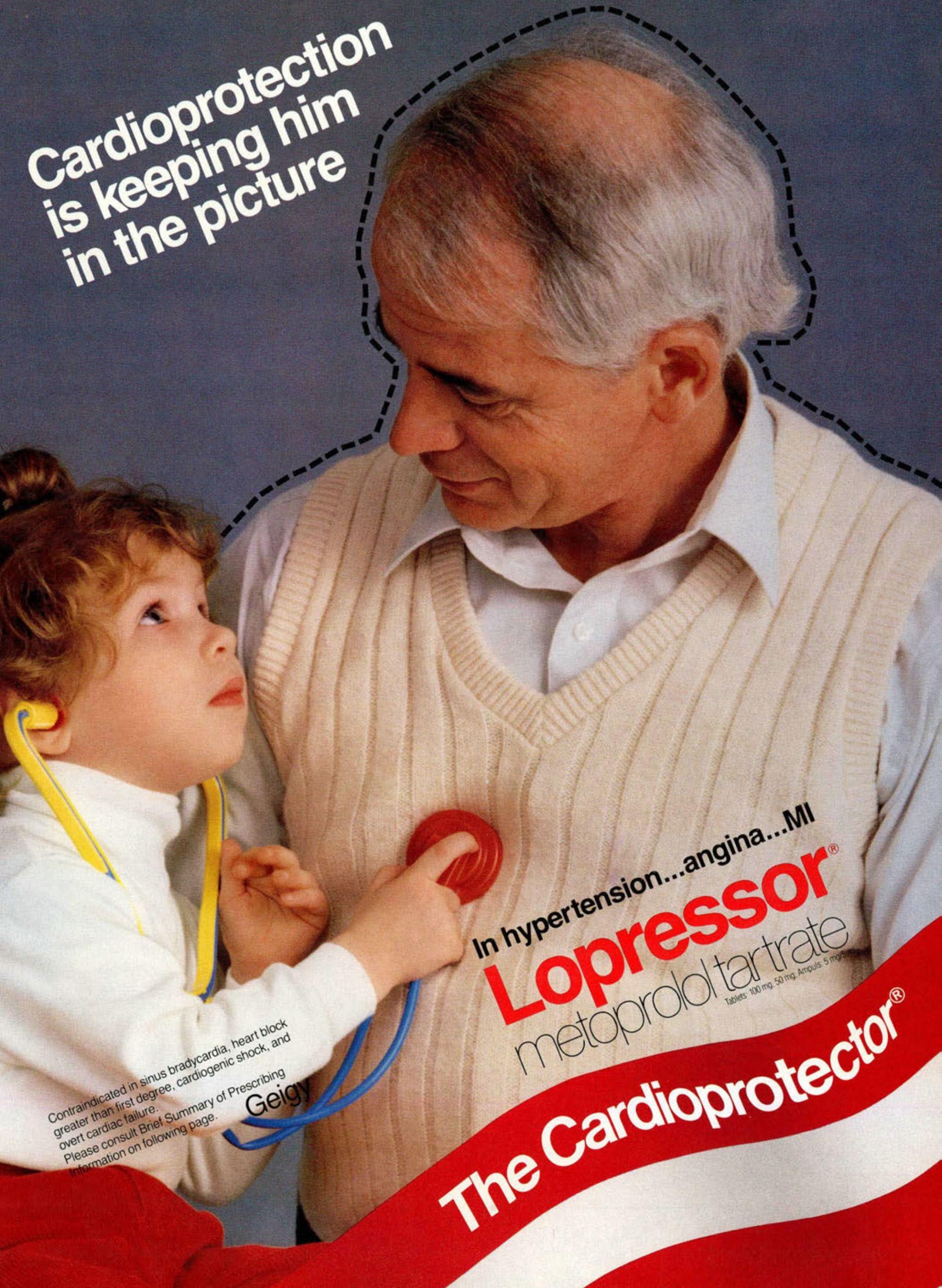




\section{Lopressor}

metoprolol tartrate USP

Tablets
Ampuls

BRIEF SUMMARY (FOR FULL PRESCRIBING

INFORMATION, SEE PACKAGE INSERT)

\section{INDICATIONS AND USAGE}

\section{Hypertension}

Lopressor tablets are indicated for the treatment of hypertension. They may be used alone or in combination with othe antihypertensive agents.

Angina Pectoris

Lopressor is indicated in the long-term treatment of angina pectoris.

Myocardial Infarction hemodynamically stable patients with definite or suspected acute myocardial infarction to reduce cardiovascular mortality. Treatment with intravenous Lopressor can be initiated as 500 as the patient's clinical condition allows (see DOSAGE AND 政 acute event (see DOSAGE AND ADMINISTRATION)

\section{CONTRAINDICATIONS}

Hypertension and Angina Lopressor is contraindicated in sinus bradycardia, heart block greater than first degree,
failure (see WARNINGS)

\section{Myocardial Infarction}

Lopressor is contraindicated in patients with a heart rate $<45$ beats/min; second-and third-degree heart block; significant first-degree heart block ( $P$-R interval $\geq 0.24 \mathrm{sec}$ ); systolic
blood pressure $<100 \mathrm{mmHg}$; or moderate-to-severe cardiac blood pressure $<100 \mathrm{~m}$
failure (see WARNINGS)

\section{WARNINGS}

\section{Hypertension and Angina} beta blockade carries the potential hazard of further depressing myocardial contractility and precipitating more severe failure. In hypertensive and angina patients who have congestive heart be administered cautiously. Both digitalis and Lopressor slow AV conduction.

In Patients Without a History of Cardiac Failure: Continued depression of the myocardium with beta-blocking agents over a period of time can, in some cases, lead to cardiac failure. At the first sign or symptom of impending cardiac failure, patients should be fully digitalized and/or given a diuretic. The respons should be observed closely. If cardiac failure continues, despite adequate digitalizati
should be withdrawn.

\section{Ischemic Heart Disease: Following abrupt cessation of} therapy with certain beta-blocking agents, exacerbations of angina pectoris and, in some cases, myocardial intarc tion have occurred. When discontinuing chronically
administered Lopressor, particularly in patients with ischemic heart disease, the dosage should be gradually reduced over a period of $1-2$ weeks and the patient should be carefully monitored. If angina markedly worsens or acute coronary insufficiency develops, Lopressor adm istration should be reinstated promptly, at least tem-
porarily, and other measures appropriate for the manage porarily, and other measures appropriate for the management of unstable angina should be taken. Patients shou therapy without the physician's advice. Because coronary artery disease is common and may be unrecognized, it may be prudent not to discontinue Lopressor therapy
abruptly even in patients treated only for hypertension.

\section{Bronchospastic Diseases: PATIENTS WITH BRONCHO} SPASTIC DISEASES SHOULD, IN GENERAL, NOT RECEIVE BETA BLOCKERS. Because of its relative beta, selectivity, $^{2}$ however, Lopressor may be used with caution in patients with bronchospastic disease who do not respond to, or cann tolerate, other antihypertensive treatment. Since beta ${ }_{1}$ selectivity is not absolute, a beta ${ }_{2}$-stimulating agent should be administered concomitantly, and the lowest possible dose of Lopressor should be used. In these circumstances it would be prudent initially to administer Lopressor in smaller doses
three times daily, instead of larger doses two times daily, to three times daily, instead of larger doses two times daily, avoid the higher plasma levels associated with the longer Major Surgery: The necessity or desirability of withdrawin beta-blocking therapy prior to major surgery is controversial: the impaired ability of the heart to respond to reflex adrenerg stimuli may augment the risks of general anesthesia and surgical procedures

Lopressor, like other beta blockers, is a competitive inhibito of beta-receptor agonists, and its effects can be reversed by administration of such agents, e.g., dobutamine or isoproterenol. However, such patients may be subject to protracted severe hypotension. Difficulty in restarting and blockers.

Diabetes and Hypoglycemia: Lopressor should be used with caution in diabetic patients if a beta-blocking agent is required. Beta blockers may mask tachycardia occurring with
hypoglycemia, but other manifestations such as dizziness and sweating may not be significantly affected.

Thyrotoxicosis: Beta-adrenergic blockade may mask certain clinical signs (e.g., tachycardia) of hyperthyroidism. Patient suspected of developing thyrotoxicosis should be managed
carefully to avoid abrupt withdrawal of beta blockade, which might precipitate a thyroid storm.

\section{Myocardial Infarction}

Cardiac Failure: Sympathetic stimulation is a vital component supporting circulatory function, and beta blockade carries the cipitatingard of depressing myocardial contractil

During treatment with Lopressor, the hemodynamic status of the patient should be carefully monitored. If heart failure occurs or persists despite appropriate treatment, Lopressor should be discontinued.
Bradycardia: Lopressor produces a decrease in sinus hear rate in most patients; this decrease is greatest among patient with high initial heart rates and least among patients with low initial heart rates. Acute myocardial infarction (particularly in the sinus rate. the particularly if associated with evidence of lowered cardiac out particularly if associated with evidence of lowered card put, atropine ( $0.25-0.5 \mathrm{mg}$ ) should be administered

Lopressor should be discontinued, and cautious administration of isoproterenol or installation of a cardiac pacemaker should e considered.

AV Block: Lopressor slows AV conduction and may produce significant first- ( $P$. $R$ interval $\geq 0.26 \mathrm{sec}$ ). Second-, or third-
degree heart block. Acute myocardial infarction also produces degree heart bi

If heart block occurs, Lopressor should be discontinued and atropine $(0.25-0.5 \mathrm{mg})$ should be administered intravenously. If treatment with atropine is not successful, cautious administration of isoproterenol

Hypotension: If hypotension (systolic blood pressure $\leq 90$ $\mathrm{mmHg}$ ) occurs, Lopressor should be discontinued, and the hemodynamic status of the patient and the extent of myocardial damage carefully assessed. Invasive monitoring of central venous, pulmonary capillary wedge, and arterial pressures may be required. Appropriate therapy with fluids, positive inotropic agents, balloon counterpulsation, or other treatment modalities should be instituted. If hypotension is associated with sinus
bradycardia or AV block, treatment should be directed at re bradycardia or AV block, treat
versing these (see above).

Bronchospastic Diseases: PATIENTS WITH BRONCHO. SPASTIC DISEASES SHOULD, IN GENERAL, NOT RECEIVE BETA BLOCKERS. Because of its relative beta, selectivity, Lopressor may be used with extreme caution in patients with bronchospastic disease. Because it is unknown to what ex tent beta 2 -stimulating agents may exacerbate myocardial ischemia and the extent of infarction, these agents should not be used prophylactically. If bronchospasm not related to tinued. A theophylline derivative or a beta, agonist may be administered cautiously, depending on the clinical conditio of the patient. Both theophyiline derivatives and beta ${ }_{2}$ agon ists may produce serious cardiac arrhythmias.

PRECAUTIONS

General

paired hepatic function.

\section{Information for Patients}

Patients should be advised to take Lopressor regularly and continuously, as directed, with or immediately following meals. a dose should be missed, the patient should take only the ext scheduled dose (without doubling it). Patients should not Patients should be advised (1) to avoid the physician mobiles and machinery or engaging in other tasks requiring alertness until the patient's response to therapy with Lopressor has been determined: (2) to contact the physician if any difficulty in breathing occurs: (3) to intorm the physician or dentist culty in breathing occurs; (3) to inform the physician or dentist
before any type of surgery that he or she is taking Lopressor. Laboratory Tests

Clinical laboratory findings may include elevated levels of serum transaminase, alkaline phosphatase, and lactate dehydrogenase.

Drug Interactions

Catecholamine-depleting drugs (e.g., reserpine) may have an additive effect when given with beta-blocking agents. Patient treated with Lopressor plus a catecholamine depletor should marked bradycardia, which may produce vertigo. syncope. or ostural hypotension

Risk of Anaphylactic Reaction. While taking beta-blockers. patients with a history of severe anaphylactic reaction to variety of allergens may be more reactive to repeated chalpatients may be unresponsive to the usual doses of epinephrine

Carcinogenesis, Mutagenesis, Impairment of Fertility Long-term studies in animals have been conducted to evaluate carcinogenic potential. In a 2-year study in rats at three ora dosage levels of up to $800 \mathrm{mg} / \mathrm{kg}$ per day, there was no increase in the development of spontaneously occurring benign or malignant neoplasms of any type. The only histologic
changes that appeared to be drug related were an increase incidence of generally mild focal accumulation of foamy macrophages in pulmonary alveoli and a slight increase in biliary hyperplasia. In a 21-month study in Swiss albino mice at three oral dosage levels of up to $750 \mathrm{mg} / \mathrm{kg}$ per day, benign lung mice receiving the highest dose than in untreated control animals. There was no increase in malignant or total (benign plus malignant) lung tumors, nor in the overall incidence of tumors
or malignant tumors. This 21 -month study was repeated in or malignant tumors. This 21 -month study was repeated in ferences were observed between treated and control mice of either sex for any type of tumo

All mutagenicity tests performed (a dominant lethal study in mice, chromosome studies in somatic cells, a Salmonella mammalian-microsome mutagenicity test, and a nucleus
anomaly test in somatic interphase nuclei) were negative. anomaly test in somatic interphase nuclei) were negative.
No evidence of impaired fertility due to Lopressor was obNo evidence of impaired fertility due to Lopressor was ob-
served in a study performed in rats at doses up to 55.5 times the maximum daily human dose of $450 \mathrm{mg}$.

Pregnancy Category C

Lopressor has been shown to increase postimplantation loss and decrease neonatal survival in rats at doses up to 55.5 times the maximum daily human dose of $450 \mathrm{mg}$. Distribution studies in mice confirm exposure of the fetus when Lopressor is administered to the pregnant animal. These studies have
revealed no evidence of impaired fertility or teratogenicity. revealed no evidence of impaired fertility or teratogenicity. There are no adequate and well-controlled studies in pregnan
women. Because animal reproduction studies are not always women. Because animal reproduction studies are not always
predictive of human response, this drug should be used during pregnancy only if clearly needed.

\section{Nursing Mothers}

Lopressor is excreted in breast milk in very small quantity. An infant consuming 1 liter of breast milk daily would receive a when Lopressor is administered to a nursing woman

Pediatric Use

ADVERSE REACTIONS

\section{Hypertension and Angina}

Most adverse effects have been mild and transient.

Central Nervous System: Tiredness and dizziness have occurred in about 10 of 100 patients. Depression has been short-term memory loss have been reported. Headache, nightmares, and insomnia have also been reported.

Cardiovascular: Shortness of breath and bradycardia have occurred in approximately 3 of 100 patients. Cold extremities: arterial insufficiency, usually of the Raynaud type; palpitations; have been reported in about 1 of 100 patients. (See CON.

TRAINDICATIONS, WARNINGS, and PRECAUTIONS.)

Respiratory: Wheezing (bronchospasm) and dyspnea have Gastrointestinal: Diarrhea has occurred in about 5 of 100 patients. Nausea, dry mouth, gastric pain, constipation,

Hypersensitive Reactions: Pruritus or rash have occurred in bout 5 of 100 patients. Worsening of psoriasis has also been

eported vision and tinnitus have also been reported.

There have been rare reports of reversible alopecia

agranulocytosis, and dry eyes. Discontinuation of the drug explicable.

The oculomucocutaneous syndrome associated with the beta blocker practolol has not been reported with Lopressor. Myocardial Infarction

Central Nervous System: Tiredness has been reported in bout 1 of 100 patients. Vertigo, sleep disturbances, hallucin and reduced libido have also been reported, but a drug rela-

onship is not clear

Cardiovascular: In the randomized comparison of Lopresso tion, the following adverse reactions were reported:

\begin{tabular}{|c|c|}
\hline & Lopressor \\
\hline $\begin{array}{l}\text { Hypotension } \\
\text { (systolic BP } \\
<90 \mathrm{mmHg} \text { ) }\end{array}$ & $27.4 \%$ \\
\hline $\begin{array}{l}\text { Bradycardia } \\
\text { (heart rate } \\
<40 \text { beats } / \mathrm{min} \text { ) }\end{array}$ & $15.9 \%$ \\
\hline $\begin{array}{l}\text { Second- or } \\
\text { third-degree } \\
\text { heart block }\end{array}$ & $4.7 \%$ \\
\hline $\begin{array}{l}\text { First-degree } \\
\text { heart block } \\
(P-R \geq 0.26 \mathrm{sec})\end{array}$ & $5.3 \%$ \\
\hline
\end{tabular}

eart failure

$27.5 \%$

$29.6 \%$

Respiratory: Dyspnea of pulmonary origin has been re.

Gortroiner than 1 of 100 patients.

Gastrointestinal: Nausea and abdominal pain have been Derted in fewer than 1 of 100 patients. Dorted, but a drug relationship is not clear.

Miscellaneous: Unstable diabetes and claudication have been reported, but a drug relatio

A variety of adverse reactions not listed above have been reported with other beta-adrenergic blocking agents and should

e considered potential adverse reactions to Lopressor.

progressing to catatonia an acute reversible syndrome char terized by disorientation for time and place, short-term memory loss, emotional lability, slightly clouded sensorium, and decreased pertormance on neuropsychometrics. Cardiovascular: Intensification of AV block (see CONTRA. INDICATIONS)

Hematologic: Agranulocytosis, nonthrombocytopenic pur-

pura, thrombocytopenic purpura.
Hypersensitive Reactions: Fever combined with aching and sore throat, laryngospasm, and respiratory distress.

OVERDOSAGE

Several cases of overdosage have been reported, some leading

to death.

Oral LDso's (mg/kg): mice, 1158-2460; rats, 3090-4670.

Signs and Symptoms

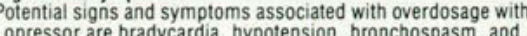
cardiac failure.

Treatment

There is no specific antidote.

In general, patients with acute or recent myocardial infarction may be more hemodynamically unstable than other pa-

Myocardial Infarction)

On the basis of the pharmacologic actions of Lopressor, the ollowing general measures should be employed:

Elimination of the Drug: Gastric lavage should be

ertormed.

Bradycardia: Atropine should be administered. If there is no response to vagal blockade, isoproterenol should be adminiseautiously. 
tient. ${ }^{57,58}$ Terbutaline has shown no evidence of teratogenicity and does not reduce uterine blood flow. ${ }^{57}$

In severe acute asthma, when repeated $\beta_{2}$ agonist aerosol treatments do not produce sufficient improvement, magnesium sulfate, $1 \mathrm{~g}$ to $1.2 \mathrm{~g}$ in $50 \mathrm{~mL}$ of normal saline solution infused intravenously over 15 to 20 minutes, may increase bronchodilator effects. ${ }^{59-61}$ The $\mathrm{Mg}^{+}+$ion can inhibit bronchial muscle contraction, reduce mediator release from mast cells, decrease acetylcholine release from bronchial cholinergic nerve endings, and produce some tranquilization. Magnesium is contraindicated in patients with renal failure or atrioventricular heart block. Magnesium may produce significant hypotension and apnea when administered too rapidly.

\section{Glucocorticoid therapy}

Glucocorticoid therapy is essential in the management of acute severe asthma. ${ }^{62}$ The Asthma Mortality Task Force concluded in 1986 that "fatalities in patients with asthma are related to withholding corticosteroid or to inadequate steroid dosage in patients with severe asthma." 63 Corticosteroids suppress the eosinophilic inflammatory response and reduce both the quantity and the tenaciousness of the asthmatic bronchial mucus. ${ }^{64}$ Additionally, corticosteroids enhance the bronchodilator responsiveness of $\beta$-agonists ${ }^{65-67}$ and anticholinergics. ${ }^{68}$ Steroids are the only medication used in status asthmaticus that reliably reduces bronchial reactivity. ${ }^{69-71}$

Prompt use of corticosteroids in the emergency treatment of severe asthma reduces the need for both hospitalization and repeated emergency care. ${ }^{72}$ No significant difference in effectiveness is noted between equivalent doses of hydrocortisone, methylprednisolone sodium succinate, and dexamethasone. ${ }^{73}$ The intravenous, oral, and repository intramuscular routes are all effective for delivering continued steroid therapy. Modest intravenous doses of hydrocortisone $(6 \mathrm{mg} / \mathrm{kg} /$ day in divided doses every 6 hours) or methylprednisolone $(40 \mathrm{mg}$ every 6 hours) are adequate in adult patients admitted with status asthmaticus. ${ }^{74,75}$ Substantially larger doses of corticosteroids are not nec- essary and increase the risk of significant side effects, including hyperglycemia, psychosis, and hypokalemia. After an initial dose of methylprednisolone, an outpatient oral tapering dose given over 7 days, starting with $32 \mathrm{mg}$ twice a day and decreasing to $0 \mathrm{mg}$ on day 8 , is effective in decreasing the relapse rate and symptoms after an acute asthmatic attack. ${ }^{76}$

Repository steroid preparations have the advantage that once administered, the patient is certain to receive the full therapeutic benefits without regard to compliance. In one study, a lower relapse rate was noted in adult asthmatic patients treated with a repository intramuscular injection of $80 \mathrm{mg}$ of methylprednisolone sodium acetate as compared with those discharged on 7-day oral prednisone tapering therapy. ${ }^{77}$

Inhaled corticosteroid therapy should commence as symptoms improve, usually within 24 to 48 hours. The inhaled steroids will begin to have therapeutic efficacy within 2 to 3 days. After status asthmaticus resolves, inhaled corticosteroids have been less than effective because of inadequate dosing in the early phases of treatment. In following up the acute severe asthmatic epidose, doses of 1000 $\mu \mathrm{g}$ to $2000 \mu \mathrm{g}$ are necessary to achieve more effective reductions of inflammation and bronchial irritability. ${ }^{78,79}$ The increased aerosol steroid dosages generally do not increase side effects but do improve pulmonary function. Spacer devices increase the therapeutic effect of aerosol steroids while reducing oral candidiasis and cough.

The most common problem seen during withdrawal of steroids is the reexacerbation of asthma. Adrenocortical suppression is a serious problem that commonly occurs when steroid therapy is withdrawn after several weeks or more of continuing treatment; however, it is rarely seen in patients who are given occasional bursts of prednisone or occasional (three or four times per year) injections of repository intramuscular steroids.

In asthmatic children, there is appropriate concern that corticosteroid therapy can produce premature closure of the epiphyses of the long bones with stunting of growth. It is less appreciated that asthma itself may retard 
growth and development and that appropriate corticosteroid therapy to control the disease can actually increase stature and improve general constitution. ${ }^{80}$ Life-threatening or potentially life-threatening episodes of asthma in the pregnant woman also require corticosteroid therapy. ${ }^{81-84}$ No demonstrable increase in fetal defects has been noted.

\section{Anticholinergics}

Anticholinergic therapy has been used to treat asthma since the $1800 \mathrm{~s}$. However, the role of atropine and its quaternary compounds atropine methylnitrate, ipratropium bromide, and oxitropium bromide (not available for use in the United States) has not been clearly defined in the treatment of asthma. The use of atropine is associated with multiple adverse effects. ${ }^{85}$ The quaternary compounds, however, are poorly absorbed from the airway and are less likely to produce systemic anticholinergic effects.

Ipratropium produces significant bronchodilation in severe ${ }^{86-88}$ and stable ${ }^{88}$ asthma; however, it is less potent than the $\beta_{2}$-agonist. $86,88-90$ There is no apparent difference in side effects between a $\beta_{2}$-agonist used alone or in combination with ipratropium. ${ }^{91-93}$ Although nebulized atropine produced an overall significantly improved forced expiratory volume in $1 \mathrm{sec}-$ ond $\left(\mathrm{FEV}_{1}\right)$ in a group with acute asthma studied by Karpel and associates, ${ }^{85} 40 \%$ of the patients had no response. In crossover studies of stable asthmatic patients, ipratropium and oxitropium produced additional bronchodilation when sequentially added to submaximally effective bronchodilating $\beta_{2}$-agonist doses. ${ }^{89,94}$

In acute asthma, effectiveness of a nebulized combination of $\beta_{2}$-agonist and ipratropium produces significantly better bronchodilation than a $\beta_{2}$-agonist alone. ${ }^{93-96}$ In the studies cited, it was found that combination therapy produced its greatest effect in those patients with the most severe impairment $\left(\mathrm{FEV}_{1}\right.$ less than or equal to $1 \mathrm{~L}$ or peak expiratory flow rate [PEFR] less than $140 \mathrm{~L} / \mathrm{min}$.) Those patients with a PEFR greater than or equal to $140 \mathrm{~L} /$ min had only slight added improvement with the combination therapy. ${ }^{93}$ Comparing $\beta_{2}$-agonist therapy alone with combination therapy,
Higgins and coworkers ${ }^{94}$ compared their results with those from two other studies. ${ }^{87-95}$ They found that ipratropium produced an extra bronchodilating effect when combined with $\beta_{2}$-agonist therapy.

Three Canadian studies have examined ipratropium and $\beta_{2}$-agonist combination nebulization therapy in children with acute severe asthma. ${ }^{86,91,97}$ They found significantly improved bronchodilation in the group treated with the ipratropium- $\beta_{2}$-agonist combination as compared with the group given a $\beta_{2}$-agonist alone. Although anticholinergics may enhance bronchodilator therapy in patients with acute severe asthma, they are not first-line drugs. They should only be used in combination with aerosol $\beta_{2}$-agonist therapy.

\section{Methylxanthines}

Once considered a cornerstone of bronchodilator therapy in the treatment of patients with asthma, theophylline is now considered a thirdline drug, judged either relatively ineffective or too toxic. ${ }^{98-113}$ Proponents of theophylline therapy had hoped that monitoring blood levels to achieve therapeutic levels while avoiding toxic levels would help make theophylline therapy more precise and less empiric. These hopes have not been realized because toxicity occurs in a significant number of patients treated with intravenous theophylline, even when blood levels are closely monitored. ${ }^{107}$ The effect of numerous medications and illnesses on the hepatic metabolism and clearance of the drug increases the toxicity potential.

The most crucial evidence against the use of theophylline in acute asthma comes from recent studies ${ }^{98-101}$ that show no significant benefit from the addition of theophylline to $\beta$ agonist therapy compared with use of a $\beta$ agonist alone. Although some investigations ${ }^{114,115}$ suggest that theophylline improves diaphragmatic contractility and delays the onset of diaphragmatic fatigue, other investigations ${ }^{116,118}$ show that theophylline has no significant clinical benefit on either diaphragmatic or accessory respiratory muscle fatigue.

\section{Hydration therapy}

Although vigorous intravenous or oral hydra- 
tion or a combination of both is commonly recommended for asthmatic patients with acute symptoms, there is little evidence to support the view that systemic hydration increases airway hydration in status asthmaticus. However, the patient with acute asthma often is mildly dehydrated and may require fluid therapy. The deficit may be corrected over the initial 24 hours by using 1.5 times the daily maintenance fluid requirement. ${ }^{118}$ Overhydration of patients may increase hydrostatic pressure in pulmonary vessels and increase the possibility of pulmonary edema. ${ }^{118}$

Chest percussion and postural drainage are contraindicated in the initial phases of treatment of status asthmaticus. These maneuvers may aggravate hypoxemia and respiratory distress.

\section{Ventilatory support}

With the increased effectiveness of aerosol bronchodilator therapy and corticosteroid therapy, airway intubation and mechanical ventilator support of patients with status asthmaticus have become less common. The risk of barotrauma to the lungs with ruptured alveoli and subsequent pneumomediastinum or pneumothorax or both is increased in status asthmaticus whether the patient is breathing spontaneously with or without ventilator support. If barotrauma has not already occurred, the best prevention is intensive aerosol bronchodilator therapy and systemic corticosteroid therapy while oxygenation is being supported. To control the risk of barotrauma, the ventilator rate and inspiratory flow should be set as low as feasible, usually between 8 and 16 breaths per minute with tidal volumes of 6 to $10 \mathrm{~mL}$ per kilogram of ideal body weight. Slower rates will allow more time for exhalation and may prevent auto-peep (increased intrathoracic pressure resulting in incomplete exhalation followed by early inhalation), which further aggravates air trapping and the risk of barotrauma. Increased intrathoracic pressure can increase the venous return to the thorax, resulting in decreased cardiac output or hypotension (or both). Inspiratory flows of $40 \mathrm{~L} /$ $\mathrm{min}$ to $50 \mathrm{~L} / \mathrm{min}$ are usually adequate.

The use of positive end-expiratory pressure
(PEEP) is contraindicated in patients with status asthmaticus because PEEP increases air trapping and intrathoracic pressure, which is already extreme in the lungs of these patients.

\section{Comment}

The optimal treatment of bronchial asthma has been the subject of controversy in recent years. This article has examined available medications, route of delivery, and dosage in an attempt to clarify the issues involved and determine the best results. The role of hydration and ventilatory support are also explored.

\section{References}

1. Bailey CD (ed): Clinics in Chest Medicine. Philadelphia, $\mathrm{Pa}$, WB Saunders Co, vol 5, No. 4, December 1984, p 555. 2. McFadden ER, Lyons HA: Arterial-blood gas tension in asthma. $N$ Engl J Med 1968;278:1027-1032.

3. Weng TR, Langer HM, Featherby EA, et al: Arterial blood gas tension and acid-base balance in symptomatic and asymptomatic asthma in childhood. Am Rev Respir Dis 1970;101:274282.

4. Harris L: Comparison of cardiorespiratory effects of terbutaline and salbutamol aerosols in patients with reversible airways obstruction. Thorax 1973;28:592-595.

5. Vathenen AS, Britton JR, Ebeden P, et al: High-dose inhaled albuterol in severe chronic airflow limitation. Am Rev Respir Dis $1983 ; 138: 850-855$.

6. Rossing TH, Fanta CH, Goldstein DH, et al: Emergency therapy of asthma: Comparison of the acute effects of parenteral and inhaled sympathomimetics and infused aminophylline. Am Rev Respir Dis 1980;122:365-371.

7. Riding WD, Dinda P, Chatterjee SS: The bronchodilator and cardiac effects of five pressure-packed aerosols in asthma. $\mathrm{Br}$ $J$ Dis Chest 1970;64:37-45.

8. Berezuk GP, Schondelmeyer SW, Seidenfeld JJ, et al: Clinical comparison of albuterol, isoetharine, and metaproterenol given by aerosol inhalation. Clin Pharm 1983;2:129-134.

9. Jenkinson SG, Light RW, George RB: Comparison of albuterol and isoproterenol aerosols in bronchial asthma. Ann Allergy 1977;39:423-424.

10. Storms WW, Hudson LD, DeGraff AC, et al: Albuterol nebulizer solution for the treatment of asthma. Ann Allergy 1985;55:779-782.

11. Tattersfield AE, McNicol MW: Salbutamol and isoproterenol. N Engl J Med 1969;281:1323-1326.

12. Riken JB, Cacace LG: Double-blind comparison of metaproterenol and isoetharine-phenylephrine solution in intermittent positive pressure breathing in bronchospastic conditions. Chest 1980;78:723-725.

13. Newhouse MT, Dolovich MB: Control of asthma by aerosols. N Engl J Med 1986;315:870-874.

14. Lee HS: Comparison of oral and aerosol adrenergic bronchodilators in asthma. J Pediatr 1981;99:805-807.

15. Shim C, Williams MH: Bronchial response to oral versus 
aerosol metaproterenol in asthma. Ann Intern med 1980;93:428431.

16. Webb J, Rees J, Clark TJH: A comparison of the effects of different methods of administration of $\beta$-2-sympathomimetics in patients with asthma. $\mathrm{Br} J$ Dis Chest 1982;76:351-357.

17. Larsson S, Svedmyr N: Bronchodilating effect and side effects of beta $\mathrm{a}_{2}$-adrenoreceptor stimulants by different modes of administration (tablets, metered aerosol, and combinations thereof). Am Rev Respir Dis 1977;116:861-869.

18. Williams SJ, Winner SH, Clark TJH: Comparison of inhaled and intravenous terbutaline in acute severe asthma. Thorax 1981;36:629-631.

19. Lawford P, Jones BJM, Milledge JS: Comparison of intravenous and nebulized salbutamol in initial treatment of severe asthma. Br Med J 1978;84.

20. Bloomfield P, Carmichael J, Petrie GR, et al: Comparison of salbutamol given intravenously and by intermittent positivepressure breathing in life-threatening asthma. $\mathrm{Br}$ Med $\mathrm{J}$ 1979;1:848-850.

21. Crompton GK: Problems patients have using pressurized aerosol inhalers. Eur J Res Dis 1982;119(suppl):101-104.

22. Epstein SW, Manning GPR, Ashley MJ, et al: Survey of the clinical use of pressurized aerosol inhalers. Can Med Assoc $J$ 1979;120:813-816.

23. Newman SP, Moren F, Pavia D, et al: Deposition of pressurized suspension aerosols inhaled through extension devices. Am Rev Respir Dis 1981;124:317-320.

24. Turner JR, Corkery KJ, Eckman D, et al: Equivalence of continuous flow nebulizer and metered-dose inhaler with reservoir bag for treatment of acute airflow obstruction. Chest 1988;93:476-481.

25. Jenkins SC, Heaton RW, Fulton TJ, et al: Comparison of domiciliary nebulized salbutamol and salbutamol from a metered-dose inhaler in stable chronic airflow limitation. Chest 1987;91:804-806.

26. Weber RW, Petty WE, Nelson HS: Aerosolized terbutaline in asthmatics. J Allergy Clin Immunol 1979;63:116-121.

27. Newman SP, Clarke SW: Therapeutic aerosols. 1-Physical and practical considerations. Thorax 1983;38:881-886.

28. Newhouse M, Dolovich M: Aerosol therapy: Nebulizer vs metered dose inhaler. Chest 1987;91:799-780.

29. Morley TF, Marozsan E, Zappasode SJ, et al: Comparison of beta-adrenergic agents delivered by nebulizer vs metered dose inhaler with InspirEase in hospitalized asthmatic patients. Chest 1988;96:1205-1210.

30. Beasley CW, O'Donnel TV: Pear shaped spacer Nebuhaler compared with nebulized solution for terbutaline administration in acute severe asthma. $N Z$ Med $J$ 1985;9:854-855.

31. Summer W, Elston R, Tharpe L, et al: Aerosol bronchodilator delivery methods. Arch Intern Med 1989;149:618-623.

32. O'Reilly, Gould G, Kendrick AH, et al: Domiciliary comparison of terbutaline treatment by metered dose inhaler with and without conical spacer in severe and moderately severe chronic asthma. Thorax 1986;41:766-770.

33. Madsen EB, Bundgaard A, Hidinger KG: Cumulative doseresponse study comparing terbutaline pressurized aerosol administered via a pearshaped spacer and terbutaline in a nebulized solution. Eur J Clin Pharmacol 1982;23:27-30.

34. Shim CS, Williams MH: Effect of bronchodilator therapy administered by canister versus jet nebulizer. J Allergy Clin Immunol 1984;73:387-390.

35. Morgan MDL, Singh BV, Frame MH, et al: Terbutaline aerosol given through pear spacer in acute severe asthma. $\mathrm{Br} \mathrm{Med}$ $J$ 1982;285:849-850.
36. Pedersen S: Treatment of acute bronchoconstriction in children with use of a tube spacer aerosol and a dry powder inhaler. Allergy 1985;40:300-304.

37. Grimwood K, Johnson-Barrett JJ, Taylor B: Salbutamol: Tablets, inhalational powder, or nebulizer? $\mathrm{Br}$ Med $J$ 1981;282:105-106.

38. Pedersen S: How to use a rotahaler. Arch Dis Child 1986;61:11-14.

39. Choo-Kang YFJ, MacDonald HL, Horne NW: A comparison of salbutamol and terbutaline aerosols in bronchial asthma. Clin Trials 1973;211:801-804.

40. Munzenberger PJ, Papaioanou HA, Massoud N: A clinical comparison of terbutaline with albuterol administered by metered-dose inhaler. Ann Allergy 1989;62:107-110.

41. Habib MP, Campbell SC, Shon BY, et al: A comparison of albuterol and metaproterenol nebulizer solutions. Ann Allergy 1987;58:421-424.

42. Racoveanu C, Stanescu DC, Manicatide M, et al: The bronchodilator effects of orciprenaline and salbutamol. Postgrad Med J 1977;47:83-86.

43. Mathijsen A: Comparative investigations on pirbuterol, salbutamol and placebo aerosols in bronchial asthma. Int $J$ Clin Pharm Biopharm 1979;17(6):237-239.

44. Mathijsen A: Pirbuterol versus orciprenaline aerosols in the treatment of bronchial asthma. Int $J$ Clin Pharm Ther Toxicol 1983;21:3:147-166.

45. Burgess CD, Flatt A, Siebers R, et al: A comparison of the extent and duration of hypokalemia following three nebulized beta-2-adrenoceptor agonists. Eur J Clin Pharmacol 1989;36:415417.

46. Allon M, Dunlay R, Copkney: Nebulized albuterol for acute hyperkalemia in patients on hemodialysis. Ann Intern Med 1989;110:426-429.

47. Schuh S, Parkin P, Rajan A, et al: High-versus low-dose frequently administered, nebulized albuterol in children with severe, acute asthma. Pediatrics 1989;83:4:513-518.

48. Barnes J, Pride NB: Dose-response curves to inhaled $\beta$ adrenoceptor agonists in normal and asthmatic subjects. $\mathrm{Br} J$ Clin Pharmacol 1983;15:677-682.

49. Kelsen SG, Kelsen DP, Fleegler BF, et al: Emergency room assessment and treatment of patients with acute asthma. Am $J$ Med 1978;64:622-628.

50. Fanta $\mathrm{CH}$, Rossing TH, McFadden ER: Emergency room treatment of asthma. Am J Med 1982;72:416-422.

51. Powell ML, Weisberger M, Gural R, et al: Comparative bioavailability and pharmacokinetics of three formulations of albuterol. J Pharm Sciences 1985;74:2:217-219.

52. Physicians' Desk Reference, ed 46. Oradell NJ, Medical Economics Co, Inc, 1992, p 2121.

53. Nelson HS, Spector SL, Whitsett TL, et al: The bronchodilator response to inhalation of increasing doses of aerosolized albuterol. J Allergy Clin Immunol 1983;72:371-375.

54. Light RW, Taylor RW, George RB: Albuterol and isoproterenol in bronchial asthma. Arch Intern Med 1979;139:639-643.

55. APBI Data Sheet Compendium 1988 to 1989. London, England, Gilian; Datapharm, 1988.

56. Schatz M, Zeiger RS, Harden KM, et al: The safety of inhaled $\beta$-agonist bronchodilators during pregnancy. J Allergy Clin Immunol 1988;82:686-695.

57. Schatz M: Tips offered for optimizing treatment of pregnant asthmatics. Allergy Observer 1989;3:3.

58. Romereo R, Lockwood C, in Niebyl Jr (ed): Drug Use in Pregnancy, ed 2. Philadelphia, Pa, Lea \& Febiger, 1988, pp 67-82. 
59. Okayoma H, Aikawa T, Okayama M, et al: Bronchodilating effects of intravenous magnesium sulfate in bronchial asthma. JAMA 1987;257:1076-1078.

60. Skobeloff EM, Spivey WH, McNamara RM, et al: Intravenous magnesium sulfate for the treatment of acute asthma in the emergency department. JAMA 1989;262:1210-1213.

61. McNamara RM, Spivey WH, Skobeloff E, et al: Intravenous magnesium sulfate in the management of acute respiratory failure complicating asthma. Ann Emerg Med 1989;197:131-133. 62. Gilder SSB: Steroids in asthma: $S$ Afr Med J 1987;2:1-9. 63. Szefler SJ, Toogood JH, Spector SL, et al: A report from the Workshop on Pharmacology: Corticosteroids. J Allergy Clin Immunol 1987;80:441-442.

64. Chung KF: Role of inflammation in the hyperactivity of the airways in asthma. Thorax 1986;77:527-537.

65. Ellul-Micallef R, Fenech FF: Effect of intravenous prednisolone in asthmatics with diminished adrenergic responsiveness. Lancet 1975;2:1269-1270.

66. Davis C, Conolly ME: Tachyphylaxis to $\beta$-adrenoceptor agonists in human bronchial smooth muscle: Studies in vitro. $\mathrm{Br} J$ Clin Pharmacol 1980;10:417-423.

67. Holgate ST, Baldwin CJ, Tatterfield AE: Beta-adrenergic agonist resistance in normal human airways. Lancet 1977;2:375377 .

68. Jolobe OMP, Lane DJ: Atropine responsiveness in asthma in relation to steroid aerosol therapy. BrJ Dis Chest 1981;75:413416.

69. Frigas E, Gleich GJ: The eosinophil and the pathology of asthma. Allergy Clin Immunol 1986;77:527-537.

70. Persson OGA: Role of plasma exudation in asthmatic airways. Lancet 1986;2:1126-1128.

71. Dutoit JZ, Salome CM, Woolcock AJ: Inhaled corticosteroids reduce the severity of bronchial hyperresponsiveness in asthma but oral theophylline does not. Am Rev Respir Dis 1987;136:1174-1178.

72. Littenberg B, Gluck EH: A controlled trial of methylprednisolone in the emergency treatment of acute asthma. $N$ Engl J Med 1986;314:3:150-152.

73. Sue MA, Kwong FK, Klaustermeyer WB: A comparison of intravenous hydrocortisone, methylprednisolone, and dexamethasone in acute bronchial asthma. Ann Allergy 1986;56:406-409.

74. Raimoudi AC, Figueroa-Casas JC, Roncoroni AJ: Comparison between high and moderate doses of hydrocortisone in the treatment of status asthmaticus. Chest 1986;89:832-835.

75. Haskell RJ, Wong BM, Hansen JE: A double-blind randomized clinical trial of methylprednisolone in status asthmaticus. Arch Intern Med 1983;143:1324-1327.

76. Fiel SB, Swartz MA, Glanz K, et al: Efficacy of short-term corticosteroid therapy in outpatient treatment of acute bronchial asthma. Am J Med 1983;75:259-262.

77. Hoffman IB, Fiel SB: Oral vs repository corticosteroid therapy in acute asthma. Chest 1988;93:11-13.

78. Li JTC, Reed CE: Proper use of aerosol corticosteroids to control asthma. Mayo Clin Proc 1989;64:205-210.

79. Grandgeorge S, Varghn L, Milavetz G, et al: Systemic and topical dose-response relationships of inhaled corticosteroid aerosols. J Allergy Clin Immunol 1987;79:201.

80. Reimer LG, Morris HG, Ellis EF: Growth of asthmatic children during treatment with alternate day steroids. $J$ Allergy Clin Immunol 1975;55:224-231

81. Bahna SL, Bjerkedahl J: The course and outcome of pregnancy in women with bronchial asthma. Acta Allergol 1972;27:397-406.
82. Gordon N, Niswander KR, Berendes H, et al: Fetal morbidity following potentially anoxigenic obstetric conditions. VII. Am J Obstet Gynecol 1970;160:421-429.

83. Schatz M, Patterson R, Zeits S, et al: Corticosteroid therapy for the pregnant asthmatic patient. JAMA 1975;233:804-807.

84. Greenberger PA, Patterson R: Beclomethasone dipropionate for severe asthma during. pregnancy. Ann Intern Med 1983;98:478-480.

85. Karpel JP, Appel D, Breidbart D, et al: A comparison of atropine sulfate and metaproterenol sulfate in the emergency treatment of asthma. Am Rev Respir Dis 1986;133:727-729.

86. Watson WTA, Becker AB, Simons ER: Comparison of ipratropium solution, fenoterol solution, and their combination administered by nebulizer and face mask to children with acute asthma. J Allergy Clin Immunol 1988;82:1012-1018.

87. Ward MJ, Fentem Ph, Smith WHR, et al: Ipratropium brodmide in acute asthma. $\mathrm{Br}$ Med $J$ 1981;282:598-600.

88. Leahy BC, Gomm SA, Allen SC: Comparison of nebulized salbutamol with nebulized ipratropium bromide in acute asthma. $\mathrm{Br} J$ Dis Chest 1983;77:159-163.

89. Grandordy BM, Thomas V, de Lauture D, et al: Cumulative dose-response curves for assessing combined effects of salbutamol and ipratropium bromide in chronic asthma. Eur Respir $J$ 1988;1:531-535.

90. Bryant DH: Nebulized ipratropium bromide in the treatment of acute asthma. Chest 1988;1:24-29.

91. Reisman J, Goldes-Sebalt M, Kazam F, et al: Frequent administration by inhalation of salbutamol and ipratropium bromide in the initial management of severe acute asthma in children. J Allergy Clin Immunol 1988;81:16-20.

92. Shenfield GM: Combination bronchodilator therapy. Drugs 1982;24:414-439.

93. O'Driscoll BR, Taylor RJ, Horsley MG, et al: Nebulized salbutamol with and without ipratropium bromide in acute airflow obstruction. Lancet 1989;2(8652):1418-1420.

94. Laitenen LA, Poppins H: Combination of oxitropium bromide and salbutamol in the treatment of asthma with pressurized aerosols. Br J Dis Chest 1986;80:179-186.

95. Rebuck AS, Chapman KR, Abboud R, et al: Nebulized anticholinergic and sympathomimetic treatment of asthma and COPD in the emergency room. Am J Med 1987;82:59-64.

96. Higgins RM, Stradling JR, Lane DJ: Should ipratropium bromide be added to beta-agonists in treatment of acute severe asthma? Chest 1988;94:718-722.

97. Beck R, Robertson C, Galdes-Sebaldt M, et al: Clinical and laboratory observations. J Pediatr 1985;107:605-607.

98. Fanta CH, Rossing TH, McFadden ER: Treatment of acute asthma: Is combination therapy with sympathomimetics and methylxanthines indicated? Am J Med 1986;80:5-10.

99. Siegel D, Sheppard D, Gelb A, et al: Aminophylline increases the toxicity but not the efficacy of an inhaled beta adrenergic agonist in the treatment of acute exacerbations of asthma. Am Rev Respir Dis 1985;132:283-286.

100. Rossing TH, Fanta CH, McFadden ER: Effect of outpatient treatment of asthma with beta agonists on the response to sympathomimetics in an emergency room. Am J Med 1983;75:781-784.

101. Rice KL, Leatherman JW, Duane PG, et al: Aminophylline for acute exacerbations of chronic obstructive pulmonary disease. Ann Intern Med 1987;107:305-309.

102. Eiriksson CE, Writer SL, Vestal RE: Theophylline-induced alterations in cardiac electrophysiology in patients with chronic obstructive pulmonary disease. Am Rev Respir Dis 1987;135:322326. 
103. O'Neill SJ, Sitar DS, Klass DJ, et al: The pulmonary disposition of theophylline and its influence on human alveolar macrophage bactericidal function. Am Rev Respir Dis 1986;134:1225-1228.

104. Kongragunta VR, Druz WS, Sharp JT: Dyspnea and diaphragmatic fatigue in patients with chronic obstructive pulmonary disease. Am Rev Respir Dis 1988;137:662-667.

105. Espinosa H, Antic R, Thornton AT, et al: The effect of aminophylline on sleep and sleep-disordered breathing in patients with obstructive sleep apnea syndrome. Am Rev Respir Dis 1987; 136:80-84.

106. Littenbert B: Aminophylline treatment in severe, acute asthma. JAMA 1988;259:1678-1684.

107. Aitken ML, Martin TR: Life-threatening theophylline toxicity not predictable by serum levels. Chest 1987;91:10-14.

108. Magnussen H, Jorres R, Hartmann V: Bronchodilator effect of theophylline preparation and aerosol fenoterol in stable asthma. Chest 1986;90:722-725.

109. Robin ED: Death from bronchial asthma. Chest 1988;93:614618.

110. Eidelman EH, Sami MH, McGregor M, et al: Combination of theophylline and albuterol for arrhythmias in severe COPD. Chest 1987;91:808-812.

111. Bowton DL, Akford PT, McLees BD, et al: The effect of aminophylline on cerebral blood flow in patients with COPD. Chest 1987;91:874-877.

112. Shin C, Williams MH: Comparison of oral aminophylline and aerosol metaproterenol in asthma. Am J Med 1981;71:452455

113. Rossing TH, Fanta CH, McFadden ER: A controlled trial of the use of single versus combined drug therapy in the treatment of acute episodes of asthma. Am Rev Respir Dis 1981;123:190-194.

114. Aubier M, DeTroyer A, Sampson M, et al: Aminophylline improves diaphragmatic contractility. $N$ Engl $J$ Med 1981;305:249-252.

115. Murciano J, Miller J, Wiles CM, et al: Effect of theophylline on diaphragmatic strength and fatigue in patients with chronic obstructive pulmonary disease. $N$ Engl $J \mathrm{Med}$ 1984;311:226-229.

116. Belman MJ, Sieck GC, Mazar A: Aminophylline and its effect on ventilatory endurance in humans Am Rev Respir Dis 1985;131:226-229.

117. Lewis MI, Belman MJ, Sieck GC: Aminophylline and fatigue of the sternomastoid muscle. Am Rev Respir Dis 1986;133:672-675.

118. Stemple DA, Mellon M: Management of acute severe asthma. Pediatr Clin North Am Aug 1984;31:879-890. 